\title{
Recommendations for establishing or renewing scientific councils in protected areas
}

\author{
Isabelle Arpin, Astrid Wallner, Thomas Scheurer \& Valerie Braun
}

Keywords: mountain protected areas, management, scientific councils

\section{Abstract}

The following recommendations stem from a workshop entitled Interface between science and mountain protected areas: The role of scientific councils, held in Chambéry (France) in June 2015. This workshop gathered together some 30 scientists and managers from all Alpine countries and different types of protected areas (PA) and allowed discussing the goals, composition, organization and management of scientific councils. While based on experiences in Alpine countries, these recommendations can be applied to managed PAs in general.

They are addressed to PA managers and scientists involved or interested in participating in scientific councils, as well as to the PA executive boards and administrations in charge of PA management and policy. They intend to help decide if and when to establish a scientific council and how to compose, organize and manage it if such a decision has been made, is planned or envisaged. Given the diversity of national regulations and practices, they remain rather general: the aim is to identify the questions to bear in mind when establishing or renewing a scientific council rather than to give predefined or definitive answers.

\section{Why establish a scientific council in a PA?}

\section{Approaching complex issues}

Science is an important resource for PA managers to address complex issues (e.g. climate change, invasive species, wildlife diseases, increasing diversity and heterogeneity of needs and wants of inhabitants and visitors) in a legitimate manner and to promote and organize valuable scientific research.

Creating a scientific council is definitely not the only solution to bring science to PAs. PAs without a scientific council can have strong, enduring and fruitful relationships with the scientific community. Gran Paradiso (Italy), Gesäuse (Austria) and Berchtesgaden (Germany) national parks are telling examples of this possibility.

However, having a scientific council might present specific and valuable advantages. The main added value of a scientific council is to allow examining complex issues collectively, from various angles and through various lenses, and hence to enrich the vision and understanding that PA managers can obtain about these issues. By broadening the scope of examination and providing room for debates, discussions within the scientific council often lead to answers and positions that differ significantly from those of individual experts and provide analyses that are superior to the sum of their individual contributions.

\section{Fostering science-based management and inserting PAs in scientific networks}

Scientific councils should ameliorate the quality and legitimacy of PA management decisions by giving them a robust scientific basis. They can produce a variety of contributions such as research proposals and programmes, evaluations of inventorying and monitoring protocols, advice about authorizations, management operations, plans and policies.
They should also facilitate the establishment of tight and fruitful relationships between PA and the scientific community, foster the development of science adapted to the PA needs, and insert PA in scientific networks, for instance as partners of LTSER (Longterm socio-economic and ecosystem research).

\section{How to compose a scientific council?}

The composition of a scientific council is central to its capacity to respond to the scientific needs of a PA. As these scientific needs vary across PAs as well as over time, the goal here is to address some general issues to be considered when designing the composition of a scientific council rather than answer this question explicitly.

Select a limited number of dedicated members following the key tasks

The PA should seek to strike a balance between having enough members to cover its expertise needs and allowing the scientific council having efficient debates and work processes.

Discussions and debates are difficult to organize if there are either too few $(<5)$ or too many members $(>25)$. A number below 10 seems reasonable if a scientific council focuses on scientific research. A number between 10 and 20 seems a good compromise to initiate and maintain collective dynamics. If more members are included, subdividing the council into working groups or commissions and designating a bureau of a limited number of members to prepare plenary meetings and handle urgent questions in-between plenary meetings might prove useful.

Members accept to dedicate part of their time free of charge to a scientific council. Motivation to sit on the council and dedicate at least a few days per year to its activities should therefore be taken into account, 
even if this motivation might be difficult to assess beforehand.

Design the scientific council as the heart of an expert network

Including all the disciplinary fields needed in a PA in a scientific council is unattainable. Rather than seeking to cover the whole range of issues that a PA might face, scientific councils should involve external specialists on an ad hoc basis.

Prefer members with high networking capacity

Members with good knowledge of the scientific community and capable of identifying and involving external scientists when needed and fostering the insertion of the PA in scientific networks and programmes are particularly helpful.

Choose members from a variety of disciplines and types of knowledge and covering the main stakes of a PA

Other aspects to be taken into account are the type of scientific activity and practice to involve in the scientific council and the nature of the represented disciplines.

The added value of scientific councils - enriching the way in which complex issues or questions are envisioned - calls for a rather open conception of science, keeping in mind that science is highly diversified and manifold. In particular, while attention must be paid to the scientific profile of members so as to ensure credibility, scientific councils could or should also include people from outside academia, e. g. high level amateurs or PA rangers.

While choosing the members, close attention should be paid to their knowledge of the specific questions raised by the PA and its management and to their experience of the conservation of the natural and cultural heritage at stake.

Deciding which disciplines should be represented on a scientific council presupposes identifying the major characteristics and stakes of the PA, with equal attention being paid to all aspects. While scientific councils have long tended to be mostly comprised of natural scientists, it becomes ever clearer that the knowledge, competencies and skills of social scientists are just as important to help PA managers address the issues they face and perform their tasks and missions. This holds especially when they have to deal with heritage appropriation, governance, conflicts of use and social or economical issues.

Mix cosmopolitan and residential knowledge holders

Another way of enriching the input of the scientific council is to include members with residential knowledge - i.e. knowledge stemming from an enduring and intensive embedment in the PA - as well as members with cosmopolitan knowledge. The for- mer have precise knowledge of the PA, might have a stronger relation to it and show more motivation in working continuously in the council. The latter can stand back more easily and enrich discussions and viewpoints with stimulating comparisons. The presence of foreign scientists in particular might be an important asset to broaden the views on local topics and should be considered and fostered, especially in transboundary PAs.

\section{Renew the scientific council regularly}

It is also important to regularly involve new members in existing scientific councils. Experienced members facilitate the dialogue with PA managers as they have had time to develop a common language and share ideas and experiences, while newcomers are important to raise new issues and debates and help create and explore hybrid spaces between science and management. Scientific councils should also mix junior members, who are aware of recent discoveries and techniques and have time to develop an enduring collaboration with PAs, and senior members with a long experience of their disciplinary field.

A scientific council should thus be renewed regularly. When its duration is not determined by law, the pace of renewal must be chosen so as to allow the development of a genuine collective dynamic while avoiding the risk of routine and weariness. A renewal frequency of four to six years seems reasonable.

\section{What time frame and validation of the com- position process?}

Anticipate and clarify the composition process

Taking into consideration all the aforementioned criteria, as well as other criteria like gender, implies that composing a scientific council is a thorny and exacting task, requiring good knowledge of the scientific community and of the PA needs, plus much thought and work. It should therefore be anticipated and the criteria used should be clarified. There is no unique recipe as the issues at stake vary from one PA to the next. It is also an ongoing process as the characteristics and needs of PAs change over time. For instance, the issues and problems faced when creating a PA usually differ from those encountered later on, so that the composition of the council should be adjusted to its evolving situation and needs.

\section{Have the composition process officially validated}

Both PA staff and scientists generally intervene and collaborate in the composition process, e.g. by suggesting names, checking if potential candidates are actually available and interested, collecting and examining application or motivation letters. Yet it is important for the scientific council's legitimacy and authority that the final list of members be officially validated by the relevant authority. 


\section{What profile and role for the chair?}

\section{A legitimate person stimulating discussions and fostering collegiality}

A Chair is generally elected by the councillors. She or he should be considered legitimate from both the scientific and the management sides. His/her role is to stimulate, facilitate and synthesize discussions within the scientific council, between the council and the PA managers, and between the council and the executive board. The concentration of responsibility and tasks in the Chair is one potential risk that should be avoided to guarantee the genuinely collegiate character of the council.

\section{How to organize a scientific council?}

At least two characteristics of PA scientific councils are important when reflecting on their organization. First, scientific councils meet only a few times a year, which implies finding ways of ensuring continuity despite intermittent physical interaction. Second, they are supposed to bring independent scientific views on issues faced by PA managers but also to enhance dialogue between scientists and PA managers and to open up new avenues that neither scientists nor managers alone could explore. Finally, another question is how to discuss issues and problems collectively while maintaining the scientific council's independence.

\section{Organize meetings and intersession work to maintain motivation}

Direct encounters and exchanges take place during physical meetings and it is important that these be organized at least once or twice a year. This is when members get to know each other, share ideas and information and forge a common language that is needed to generate collective rather than individual appreciation and understanding of issues and questions. However, physical meetings alone cannot ensure the scientific councils' continuity. Exchanges between meetings through emails or some electronic platform might be an effective way of maintaining the members' motivations and commitment.

Encourage discussions with PA staff, allow time for debates and space for expression of divergences and uncertainty

A scientific council is much more than the mere list of its members. It is also the sum of the relationships between the scientific council's members and the PA staff. Participation of staff in the meetings and more generally in the scientific council's activities is essential to provide the members with accurate information about the situations discussed and the PA needs but also to discuss the issues at stake from both the managers' and the scientists' viewpoints. Joint presentations by scientists and PA staff, or field visits and trips might be appropriate means of fostering exchanges and sharing of views. The participation of the PA staff also allows creating and exploring hybrid spaces and opening up new avenues, provided sufficient time is allowed for in-depth discussions and debates. The meetings' agendas should be prepared accordingly and not be overloaded.

Simultaneously, scientists should also be able to provide independent and nuanced advice. Reaching a consensus is not always the best possible option and the scientific council should be able to express views and advice that conflicts with the PA's interests and strategies. Moreover, there should be room for the expression of uncertainty and divergences or disagreements within the scientific council itself.

\section{How to manage the scientific council?}

Sharing information, data and experiences, developing joint projects and exploring new spaces and futures demands more than just gathering together scientists and PA staff. The scientific council should also be managed in a way that allows this to happen. Genuine support from the PA or a research institution to prepare and organize the scientific council's meetings and activities - which entails some financial effort -, appears to be a key factor of success here. The distribution of tasks between the participants, both scientists and PA staff, in the councils is another important aspect to consider.

Ensure close and enduring cooperation between the scientific council and the PA

Members alone cannot prepare and organize the scientific council's meetings and activities in a satisfactory manner in the long term and they should be strongly supported by the PA, for instance to ensure the council's secretariat. Designating one employee of the PA scientific department, if there is one, to liaise with the scientific council, in close collaboration with the Chair, has proven to be a major asset. This person should be carefully chosen and his / her importance for the functioning of the scientific council should be fully acknowledged. She or he should have good knowledge of the scientific community and networks as well as a complete overview of the PA activities to stimulate the interaction between the PA staff and the scientific council's members. She or he should also have a wide range of other - notably organizational, relational and sometimes political - competences and skills and contribute to the friendliness of meetings, which is an important factor for the members' motivation.

\section{Enable members to take active roles and} responsibility in the long term

Some individuals play a major role in the scientific council. This is especially true of the Chair and, if any, of the PA staff in charge of the liaison with the scientific council. However, it is important that tasks be dis- 
tributed between all participants, to avoid concentrating responsibility and work on a small circle, on a duo or on a single individual, as this would generate loss of collegiality and motivation of other participants. It is important to allow all participants to become and remain actively involved in the design and performance of the council's activities.

\section{Conclusions}

As previously mentioned, having a scientific council is not compulsory for good research projects and strong scientific input to PA management. The recommendations presented here aim to identify the issues to bear in mind when considering establishing or renewing a scientific council. They are certainly not exclusive and are meant to contribute to an effective contribution of scientific councils to PA development and management.

Five recommendations appear to be of the utmost importance and should be finally recalled:

1. Adopt a broad concept of science: include a diversity of disciplines and types of knowledge.

2. Keep the council relatively small, with well qualified and highly committed members, and turn to external specialists on an ad hoc basis.

3. Ensure an enduring and strong liaison between the council and the PA, by at least one designated PA staff member.

4. Distribute the tasks between all participants members of the scientific council and PA staff to ensure collegiality and maintain motivation and commitment.

5. Keep choices open: adjust the composition, organization and management of the scientific council to the evolving situation and needs of the PA.

\section{Acknowledgements}

We would like to thank all the participants of the workshop on The role of scientific councils, held in Cham- béry (France) in June 2015 for their inputs to this text: Bernard Bal, Carole Birck, Massimo Bocca, Philippe Bourdeau, Jean-Jacques Brun, Olga Churakova, Arnaud Cosson, Jean-Marcel Dorioz, Matej Gabrovec, Fabien Hoblea, Heidi Humer-Gruber, Daniel Kreiner, Gilles Landrieu, Jean-François Lopez, Grégory Loucougaray, Emmanuel Michau, Robert Moutard, Michele Ottino, Guido Plassmann, Neil Quayle, Gaëlle Ronsin, Henri Rougier, Dominik Siegrist, Edouard Simonian, Sophie Tocreau, Michael Vogel, Chris Walzer

\section{Authors}

\section{Isabelle Arpin}

is a sociologist at the Grenoble Centre of Irstea (national research institute of science and technology for environment and agriculture). She studies contemporary ways of investigating and managing nature and is particularly interested in the interface of scientists and nature managers.

\section{Astrid Wallner}

is the coordinator for research on Swiss parks. She studied social anthropology and geography at the University of Zurich (Switzerland) and worked on the local acceptance of protected areas in Switzerland and the Ukraine.

\section{Thomas Scheurer}

is executive manager of the Research Council of the Swiss National Park and the International Scientific Committee for Alpine Reserach (ISCAR) at the Swiss Academies of Arts and Sciences.

\section{Valerie Braun}

works at the Institute for Interdisciplinary Mountain Research and is managing editor of eco.mont. 